\title{
Ribosomal Protein S3 Immunoreactivity in the Young, Adult and Aged Gerbil Hippocampus
}

\author{
Choong Hyun $\mathrm{LEE}^{1)}$, Ki-Yeon $\mathrm{YOO}^{2)}$, Jung Hoon $\mathrm{CHOI}^{3)}$, In $\mathrm{Koo} \mathrm{HWANG}^{4)}$, Soo Young $\mathrm{CHOI}^{5)}$ and Moo-Ho WON ${ }^{6}$ * \\ ${ }^{1)}$ Laboratory of Veterinary Pharmacology, College of Veterinary Medicine, Seoul National University, Seoul 151-742, ${ }^{2)}$ Institute of \\ Natural Medicine, Hallym University, Chuncheon 200-702, ${ }^{3)}$ Department of Anatomy, College of Veterinary Medicine, Kangwon \\ National University, Chuncheon, 200-701, 4) Department of Anatomy and Cell Biology, College of Veterinary Medicine, and Research \\ Institute for Veterinary Science, Seoul National University, Seoul 151-742, ${ }^{5}$ Department of Biomedical Sciences and Research Institute \\ for Bioscience and Biotechnology, Hallym University, Chuncheon 200-702 and ${ }^{6)}$ Department of Neurobiology, School of Medicine, \\ Kangwon National University, Chuncheon, 200-701, South Korea
}

(Received 7 June 2010/Accepted 2 October 2010/Published online in J-STAGE 15 October 2010)

ABSTRACT. Ribosomal protein S3 (rpS3) is well known to participate in DNA repair mechanisms. In the present study, we compared rpS3 immunoreactivity and its protein levels in the hippocampus among young, adult and aged gerbils. In the postnatal month (PM) 3 group as the young, $\mathrm{rpS} 3$ immunoreaction was observed in pyramidal and non-pyramidal cells of the hippocampus proper and in granule and polymorphic cells of the dentate gyrus. In the PM 12 group as adult and 24 group as the aged, $\mathrm{rpS}$ immunoreactivity in the hippocampus was decreased compared to the PM 3 group. Western blot analysis showed that rpS3 levels were decreased with time; lowest at PM 24. These results indicate that $\mathrm{rpS} 3$ immunoreactivity and protein levels were markedly decreased in the aged gerbil hippocampus. KEY WORDS: aging, DNA repair, gerbil, hippocampus, ribosomal protein S3.

Aging is related to neuropathological, neurochemical, structural and functional alterations in the central nervous system $[8,17]$. These alterations have been associated with accumulation of DNA damage, generation of various oxidants and decrease of antioxidant enzymes during aging [1, $22,23]$. In addition, reduced DNA repair ability plays an important role in the aging process [21]. Among various brain regions, the hippocampus, critically involved in cognitive processes such as learning and memory, has been known as a vulnerable and sensitive region most affected by aging process and exhibits age-related morphological and physiological changes $[5,11,20]$.

Ribosomes are large ribonucleoprotein machines, which synthesize proteins from transcribed mRNA. They are composed heterodimerically of large and small subunits, and interaction between subunits regulates a fundamental property of translation [4]. Ribosomal protein S3 (rpS3), a component of the $40 \mathrm{~S}$ ribosomal subunit, has multiple functions such as protein translation, transcription and apoptotic pathways $[12,15,16,27]$. Especially, $r p S 3$ is well known to participate in DNA repair mechanisms such as apurinic/apyrimidinic lyase activity on abasic DNA sites and DNA glycosylase activity on 8-oxoguanine [3, 13, 14, 28, 29]. In addition, our previous study showed that induction of $\mathrm{rpS} 3$ in the hippocampal CA1 region was associated with a compensatory DNA repair mechanisms after an ischemic insult in gerbils [9].

Although many studies have been focused on the various roles of $\mathrm{rpS} 3$, there is no study on $\mathrm{rpS} 3$ expression in the

\footnotetext{
* Correspondence to: Prof. Won, M.-H., Department of Neurobiology, School of Medicine, Kangwon National University, Chuncheon 200-701, South Korea.

e-mail: mhwon@kangwon.ac.kr
}

brain during normal aging. In the present study, therefore, we investigated age-related changes in $\mathrm{rpS} 3$ immunoreactivity and its protein levels in hippocampal subregions in young, adult and aged gerbils.

We used the male Mongolian gerbils (Meriones unguiculatus) obtained from the Experimental Animal Center, Hallym University, Chuncheon, South Korea, at postnatal month 3 (PM 3) as the young, PM 12 as the adult, and PM 24 as the aged. The animals ( $n=14$ at each age) were housed in a conventional state under adequate temperature $\left(23^{\circ} \mathrm{C}\right)$ and humidity $(60 \%)$ control with a 12-hr light/12-hr dark cycle, and provided with free access to food and water. The procedures for handling and caring for animals adhered to the guidelines that are in compliance with the current international laws and policies (NIH Guide for the Care and Use of Laboratory Animals, NIH Publication No. 85-23, 1985, revised 1996), and they were approved by the Institutional Animal Care and Use Committee at Hallym's Medical Center. All of the experiments were conducted to minimize the number of animals used and the suffering caused by the procedures used in the present study.

The animals ( $n=7$ per group) were anesthetized with pentobarbital sodium and perfused transcardially with $0.1 \mathrm{M}$ phosphate-buffered saline (PBS, $\mathrm{pH} 7.4$ ) followed by $4 \%$ paraformaldehyde in $0.1 \mathrm{M} \mathrm{PBS}$ ( $\mathrm{pH} 7.4$ ). The brains were removed and postfixed with the same solution for $6 \mathrm{hr}$. The tissues were cryoprotected by infiltration with $30 \%$ sucrose overnight. The brain tissues were then frozen and sectioned with a cryostat at $30 \mu \mathrm{m}$, and consecutive sections were collected in six-well plates containing $0.1 \mathrm{M}$ PBS.

Production and purification of $\mathrm{rpS} 3$ monoclonal antibody to the enzyme were performed as previously described [2, 9]. The antibody was produced by cell fusion after immuni- 
zation of BALB/c mice with purified human $\mathrm{rpS} 3$.

To ensure that immunohistochemical data were comparable between groups, the free-floating sections were carefully processed under the same conditions. The sections were sequentially treated with $0.3 \%$ hydrogen peroxide $\left(\mathrm{H}_{2} \mathrm{O}_{2}\right)$ in PBS for 30 min and 10\% normal goat serum in $0.05 \mathrm{M}$ PBS for $30 \mathrm{~min}$. They were next incubated with diluted mouse anti-rpS3 overnight at room temperature and subsequently exposed to biotinylated goat anti-mouse $\operatorname{IgG}(1: 200$, Vector, Burlingame, CA) and streptavidin peroxidase complex (1:200, Vector). Then, the sections were visualized by staining with 3,3 '-diaminobenzidine in $0.1 \mathrm{M}$ Tris- $\mathrm{HCl}$ buffer ( $\mathrm{pH}$ 7.2) and mounted on gelatin-coated slides. After dehydration the sections were mounted with Canada balsam (Kanto, Tokyo, Japan). A negative control test was carried out using pre-immune serum instead of primary antibody in order to establish the specificity of the immunostaining. The negative control resulted in the absence of immunoreactivity in all structures.

The studied tissue sections were selected according to anatomical landmarks corresponding to AP -1.4 to $-1.8 \mathrm{~mm}$ of the gerbil brain atlas [18]. Ten sections per animal were selected to quantitatively analyze $\mathrm{rpS} 3$ immunoreactivity. Digital images of the hippocampal subregions were captured with an AxioM1 light microscope (Carl Zeiss, Germany) equipped with a digital camera (Axiocam, Carl Zeiss, Germany) connected to a PC monitor. Semi-quantification of the immunostaining intensity of $\mathrm{rpS} 3$ in the stratum pyramidale and granule cell layer was evaluated with digital image analysis software (MetaMorph 4.01, Universal Imaging Corp.). The mean intensity of $\mathrm{rpS} 3$ immunostaining was measured by a $0-255$ gray scale system (white to dark signal corresponded from 255 to 0 ). Based on this approach, the level of immunoreactivity was scaled as,, \pm+ or ++ , representing no staining (gray scale value: $\geq 200$ ), weakly positive (gray scale value: 150-199), moderate (gray scale value: $100-149$ ), or strong (gray scale value: $\leq 99$ ), respectively. The number of rpS3 immunoreactive non-pyramidal and polymorphic cells per section of the hippocampus was counted using an image analyzing system equipped with a computer-based CCD camera (software: Optimas 6.5, CyberMetrics, Scottsdale, AZ). Cell counts were obtained by averaging the counts from the sections taken from each animal.

To confirm change in rpS3 levels in the hippocampus at various ages, animals at each ages $(n=7)$ were used for western blot analysis. After sacrificing animals, the hippocampus was removed. The tissues were then homogenized in 50 $\mathrm{mM}$ PBS (pH 7.4) containing $0.1 \mathrm{mM}$ ethylene glycol bis (2-aminoethyl ether)-N,N,N',N' tetraacetic acid ( $\mathrm{pH} 8.0$ ), $0.2 \%$ Nonidet P-40, $10 \mathrm{mM}$ ethylendiamine tetraacetic acid (pH 8.0), $15 \mathrm{mM}$ sodium pyrophosphate, $100 \mathrm{mM} \beta$-glycerophosphate, $50 \mathrm{mM} \mathrm{NaF}, 150 \mathrm{mM} \mathrm{NaCl}, 2 \mathrm{mM}$ sodium orthovanadate, $1 \mathrm{mM}$ phenylmethylsulfonyl fluoride and 1 $\mathrm{mM}$ dithiothreitol (DTT). After centrifugation at 10,000 g, the protein level in the supernatants was determined using a Micro BCA protein assay kit with bovine serum albumin as a standard (Pierce Chemical, Rockford, IL). Aliquots containing $20 \mu \mathrm{g}$ of total protein were boiled in loading buffer containing $150 \mathrm{mM}$ Tris ( $\mathrm{pH} 6.8$ ), $3 \mathrm{mM}$ DTT, 6\% SDS, $0.3 \%$ bromophenol blue and $30 \%$ glycerol. The aliquots were then loaded onto a $10 \%$ polyacrylamide gel. After electrophoresis, the gels were transferred to nitrocellulose transfer membranes (Pall Corp., East Hills, NY). To reduce background staining, the membranes were incubated with 5\% non-fat dry milk in PBS containing $0.1 \%$ Tween 20 for $45 \mathrm{~min}$, followed by incubation with mouse anti-rpS3 antiserum or mouse anti- $\beta$-actin (1:5,000, Sigma), peroxidaseconjugated goat anti-mouse IgG (Sigma) and an ECL kit (Pierce Chemical). These two proteins were detected using different lane.

The result of the western blot analysis was scanned, and densitometric analysis for the quantification of the bands was done using Scion Image software (Scion Corp., Frederick, MD), which was used to count relative optical density (ROD): A ratio of the ROD was calibrated as \%, with PM 3 designated as $100 \%$.

Differences of the mean cell count and ROD among the groups were statistically analyzed by a two-way ANOVA SPSS program and the means assessed using Duncan's multiple-range test. Statistical significance was considered at $P<0.05$.

In the PM 3 group, rpS3 immunoreaction was detected in pyramidal cells of the stratum pyramidale and in non-pyramidal cells of the strata oriens and radiatum in the hippocampus proper, and in granule cells of the granule cell layer and in polymorphic cells of the polymorphic layer in the dentate gyrus (Fig. 1A, 1D and 1G). In this group, rpS3 immunostaining intensity was strong (Table 1). rpS3 immunoreactions in the hippocampus proper and the dentate gyrus were decreased at PM 12 compared to the PM 3, and maintained until PM 24 (Table 1, Fig. 1). In the hippocampus proper, the number of rpS3-immunoreactive non-pyramidal cells was significantly decreased in the PM 12 and 24 groups; the number of rpS3-immunoreactive non-pyramidal cells was $153.4 \pm 6.4$ (mean \pm SEM), $108.1 \pm 4.8$ and 104.2 \pm 5.2 at PM 3, PM 12 and PM 24, respectively. However, the number of rpS3-immunoreactive polymorphic cells in the dentate gyrus was not significantly changed (data not shown).

In the western blot study, we found that age-dependent change pattern in rpS3 protein levels in the gerbil hippocampus was generally similar to the immunohistochemical changes. rpS3 protein levels were decreased with time. In the PM 24 group, rpS3 protein level in the hippocampus was significantly lower than that in the PM 3 group (Fig. 2).

In the present study, we used Mongolian gerbils as experimental animal. The Mongolian gerbil has a relatively short lifespan, and it is genetically homogeneous. The mean survival (50\%) lifespan of gerbils is about 120 weeks, and the oldest lifespan is about 200 weeks [26].

In this study, rpS3 immunoreaction was observed in the hippocampus proper and dentate gyrus of gerbils. This result is consistent with previous studies, which showed that 

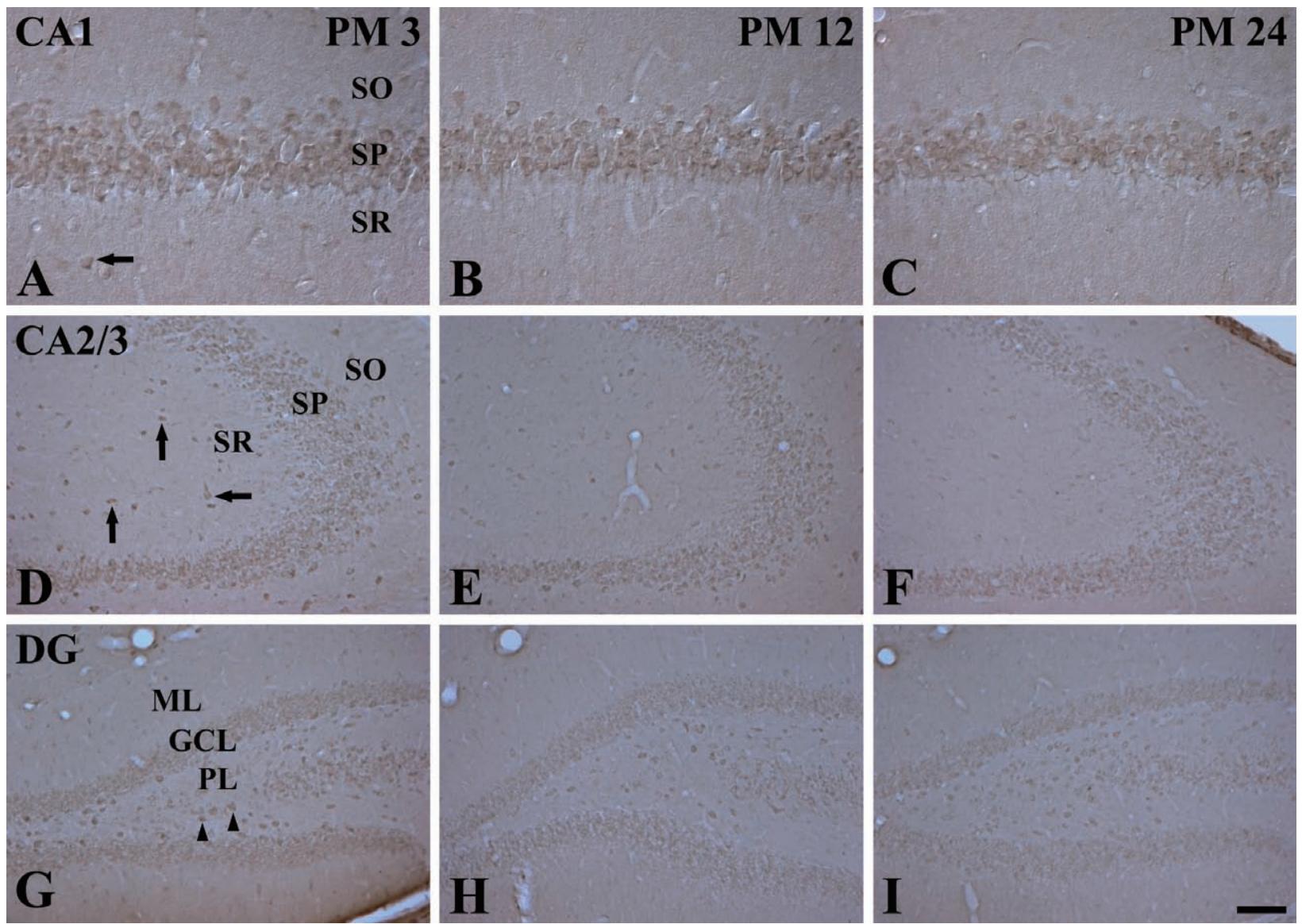

Fig. 1. Immunohistochemistry for rpS3 in the hippocampus proper (CA1, A-C; CA2/3, D-F) and dentate gyrus (G-I) at PM 3 (A, D, G), PM 12 (B, E, H) and PM 24 (C, F, I). In the PM 3 group, rpS3 immunoreaction is detected in both pyramidal and non-pyramidal cells (arrows), and in granule cells of the granule cell layer (GCL) and in polymorphic cells (arrowheads) of the polymorphic layer (PL). rpS3 immunoreactivity is decreased at PM 12 and 24. CA, conus ammonis; DG, dentate gyrus; SO, stratum oriens; SP, stratum pyramidale; SR, stratum radiatum; ML, molecular layer. Scale bar=50 (A-C), 100 (D-I) $\mu \mathrm{m}$.

Table 1. Semi-quantifications of $\mathrm{rpS} 3$ immunostaining intensity in pyramidal and granule cells of the gerbil hippocampus during normal aging

\begin{tabular}{lccc}
\hline & \multicolumn{3}{c}{ Postnatal Month (PM) } \\
& PM 3 & PM 12 & PM 24 \\
\hline Pyramidal cells & ++ & + & + \\
Granule cells & + & \pm & \pm \\
\hline The intensity of immunostaining was measured by a $0-255$ \\
gray scale system (white to dark signal corresponded from 255 \\
to 0). Based on this approach, the level of immunoreactivity \\
was scaled as - , \pm , + or ++, representing no staining (gray scale \\
value: $\geq 200$ ), weakly positive (gray scale value: $150-199$ ), \\
moderate (gray scale value: $100-149$ ), or strong (gray scale \\
value: $\leq$ 99), respectively.
\end{tabular}

rpS3 immunoreactive neurons were predominantly observed in the hippocampus including hippocampal CA1 region $[2,9]$. We also compared rpS3 immunoreactivity in the hippocampus at young, adult and aged stages. rpS3 immunoreaction in the hippocampus was decreased at adult
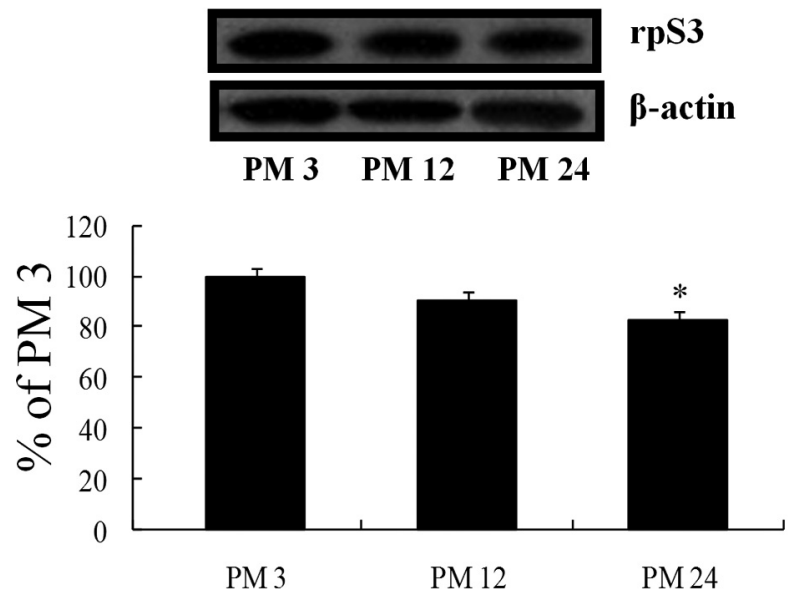

Fig. 2. Western blot analysis of rpS3 in the gerbil hippocampus derived from various age stages. The relative optical density (ROD) of immunoblot band is represented as \% values ( $n=7$ per group; * $P<0.05$, significantly different from the PM 3 group). The bars indicate the means \pm SEM. 
and aged stages compared to the young. In addition, agedependent changes in $\mathrm{rpS} 3$ protein levels were somewhat similar to the immunohistochemical changes. It is likely that age-dependent decrease in $\mathrm{rpS} 3$ protein levels might be due to the decreased concentration of rpS3 in the hippocampus as well as decreased number of rpS3-immunoreactive non-pyramidal cells. In the present study, we observed that the number of rpS3-immunoreactive non-pyramidal cells in the hippocampus proper was significantly decreased. This result was somewhat consistent with a previous study which showed the relationship between aging and interneuron in the hippocampus [24]. They showed the age-related reduction in the number of glutamic acid decarboxylase 67 (GAD67)-immunoreactive interneurons in the rat hippocampus, and urged that this reduction was due to loss of GAD67 expression in interneurons rather than interneuron degeneration. However, we did not observed any significant changes in the number of rpS3-immunoreactive polymorphic cells in the dentate gyrus. Another study examined age-related changes in senescence-associated beta-galactosidase (SA-beta-GAL), a widely used marker for cellular senescence, and showed that SA-beta-GAL-positive cells were not observed in the aged rat dentate gyrus $[6,19]$. Therefore, these and our result might indicate that senescence in the dentate gyrus is different compared to that in the hippocampus proper.

Previous studies reported the relationship between DNA repair capacity and aging process. Deficient DNA repair might play an important role during normal aging and relate to the pathology of age-related neurodegeneration [10]. It has also been known that lack of upregulation of mitochondrial DNA glycosylase activity and reduced DNA repair activity are observed in the mouse hippocampus during aging [7]. They have urged that this phenomenon might be associated with the age-related accumulation of mitochondrial DNA lesions in the hippocampus and the increased susceptibility to functional decline. Another study showed that Poly (ADP-ribose) polymerase (PARP) activity was significantly decreased in the hippocampus of aged rats [25]. They suggested that the significant decrease of PARP activity in the hippocampus was closely related to lower DNA repair ability and higher vulnerability against toxic insults. These previous studies are consistent with our present results that rpS3, involved in DNA repair mechanisms, immunoreactivity and protein levels were decreased in the hippocampus of aged gerbils. It is likely that the reduced rpS3 may be related to the lower activity of DNA repair in the aged gerbils.

In conclusion, our present study indicates that $\mathrm{rpS} 3$ immunoreactivity and protein levels are altered in the gerbil hippocampus during normal aging, showing that $\mathrm{rpS} 3$ immunoreactivity and protein levels are markedly decreased in the aged hippocampus.

ACKNOWLEDGMENTS. The authors would like to thank Mr. Seung Uk Lee and Ms. Hyun Sook Kim for their technical help in this study. This work was supported by Mid- career Researcher Program from the NRF Grant funded by the MEST (2009-0086319), and by the Regional Core Research Program funded by the Korea Ministry of Education, Science and Technology (Medical \& Bio-material Research Center).

\section{REFERENCES}

1. Cardozo-Pelaez, F., Brooks, P. J., Stedeford, T., Song, S. and Sanchez-Ramos, J. 2000. DNA damage, repair, and antioxidant systems in brain regions: a correlative study. Free Radic. Biol. Med. 28: 779-785.

2. Choi, S. H., Kim, S. Y., An, J. J., Lee, S. H., Kim, D. W., Won, M. H., Kang, T. C., Park, J., Eum, W. S., Kim, J. and Choi, S. Y., 2006. Immunohistochemical studies of human ribosomal protein S3 (rpS3). J. Biochem. Mol. Biol. 39: 208-215.

3. Deutsch, W. A., Yacoub, A., Jaruga, P., Zastawny, T. H. and Dizdaroglu, M. 1997. Characterization and mechanism of action of Drosophila ribosomal protein S3 DNA glycosylase activity for the removal of oxidatively damaged DNA bases. $J$. Biol. Chem. 272: 32857-32860.

4. Doudna, J. A. and Rath, V. L. 2002. Structure and function of the eukaryotic ribosome: the next frontier. Cell 109: 153-156.

5. Geinisman, Y., Detoledo-Morrell, L., Morrell, F. and Heller, R. E. 1995. Hippocampal markers of age-related memory dysfunction: behavioral, electrophysiological and morphological perspectives. Prog. Neurobiol. 45: 223-252.

6. Geng, Y.-Q., Guan, J.-T., Xu, X.-H. and Fu, Y.-C. 2010. Senescence-associated beta-galactosidase activity expression in aging hippocampal neurons. Biochem. Biophys. Res. Commun. 396: 866-869.

7. Gredilla, R., Garm, C., Holm, R., Bohr, V. A. and Stevnsner, T. 2010. Differential age-related changes in mitochondrial DNA repair activities in mouse brain regions. Neurobiol. Aging 31: 993-1002.

8. He, W.-B., Zhang, J.-L., Hu, J.-F., Zhang, Y., Machida, T. and Chen, N.-H. 2008. Effects of glucocorticoids on age-related impairments of hippocampal structure and function in mice. Cell. Mol. Neurobiol. 28: 277-291.

9. Hwang, I. K., Yoo, K.-Y., Kim, D. W., Kim, S. Y., Park, J. H., Ryoo, Z. Y., Kim, J., Choi, S. Y. and Won, M.-H. 2008. Ischemia-induced ribosomal protein S3 expressional changes and the neuroprotective effect against experimental cerebral ischemic damage. J. Neurosci. Res. 86: 1823-1835.

10. Imam, S. Z., Karahalil, B., Hogue, B. A., Souza-Pinto, N. C. and Bohr, V. A. 2006. Mitochondrial and nuclear DNA-repair capacity of various brain regions in mouse is altered in an agedependent manner. Neurobiol. Aging 27: 1129-1136.

11. Jack, C. R. Jr., Petersen, R. C., Xu, Y., O'Brien, P. C., Smith, G. E., Ivnik, R. J., Boeve, B. F., Tangalos, E. G. and Kokmen, E. 2000. Rates of hippocampal atrophy correlate with change in clinical status in aging and AD. Neurology 55: 484-489.

12. Jang, C.-Y., Lee, J. Y. and Kim, J. 2004. RpS3, a DNA repair endonuclease and ribosomal protein, is involved in apoptosis. FEBS Lett. 560: 81-85.

13. Jung, S.-O., Lee, J. Y. and Kim, J. 2001. Yeast ribosomal protein S3 has an endonuclease activity on AP DNA. Mol. Cells 12: 84-90.

14. Kim, J., Chubatsu, L. S., Admon, A., Stahl, J., Fellous, R. and Linn, S. 1995. Implication of mammalian ribosomal protein S3 in the processing of DNA damage. J. Biol. Chem. 270: 13620 13629. 
15. Kim, S. H., Lee, J. Y. and Kim, J. 2005. Characterization of a wide range base-damage-endonuclease activity of mammalian rpS3. Biochem. Biophys. Res. Commun. 328: 962-967.

16. Kim, S. H. and Kim, J. 2006. Reduction of invasion in human fibrosarcoma cells by ribosomal protein $\mathrm{S} 3$ in conjunction with Nm23-H1 and ERK. Biochim. Biophys. Acta 1763: 823-832.

17. Lister, J. P. and Barnes, C. A. 2009. Neurobiological changes in the hippocampus during normative aging. Arch. Neurol. 66: 829-833.

18. Loskota, W. J., Lomax, P. and Verity, M. A. 1974. A Stereotaxic Atlas of the Mongolian Gerbil Brain (Meriones unguiculatus). Ann Arbor Science Publishers Inc., Ann Arbor, Michigan.

19. Park, Y.-Y., Lee, S., Karbowski, M., Neutzner, A., Youle, R. J. and Cho, H. 2010. Loss of MARCH5 mitochondrial E3 ubiquitin ligase induces cellular senescence through dynaminrelated protein 1 and mitofusin 1. J. Cell Sci. 123: 619-626.

20. Rosenzweig, E. S. and Barnes, C. A. 2003. Impact of aging on hippocampal function: plasticity, network dynamics, and cognition. Prog. Neurobiol. 69: 143-179.

21. Rutten, B. P. F., Korr, H., Steinbusch, H. W. M. and Schmitz, C. 2003. The aging brain: less neurons could be better. Mech. Ageing Dev. 124: 349-355.

22. Shigenaga, M. K., Hagen, T. M. and Ames, B. N. 1994. Oxidative damage and mitochondrial decay in aging. Proc. Natl. Acad. Sci. U. S. A. 91: 10771-10778.
23. Smigrodzki, R., Parks, J. and Parker, W. D. 2004. High frequency of mitochondrial complex I mutations in Parkinson's disease and aging. Neurobiol. Aging 25: 1273-1281.

24. Stanley, D. P. and Shetty, A. K. 2004. Aging in the rat hippocampus is associated with widespread reductions in the number of glutamate decarboxylase-67 positive interneurons but not interneuron degeneration. J. Neurochem. 89: 204-216.

25. Strosznajder, J. B., Jeśko, H. and Strosznajder, R. P. 2000. Age-related alteration of poly(ADP-ribose) polymerase activity in different parts of the brain. Acta Biochim. Pol. 47: 331337.

26. Troup, G. M., Smith, G. S. and Walford, R. L. 1969. Life span, chronologic disease patterns, and age-related changes in relative spleen weights for the mongolian gerbil (Meriones unguiculatus). Exp. Gerontol. 4: 139-143.

27. Wan, F., Anderson, D. E., Barnitz, R. A., Snow, A., Bidere, N., Zheng, L., Hegde, V., Lam, L. T., Staudt, L. M., Levens, D., Deutsch, W. A. and Lenardo, M. J. 2007. Ribosomal protein S3: a KH domain subunit in NF- $\kappa B$ complexes that mediates selective gene regulation. Cell 131: 927-939.

28. Wool, I. G. 1996. Extraribosomal functions of ribosomal proteins. Trends Biochem. Sci. 21: 164-165.

29. Yacoub, A., Augeri, L., Kelley, M. R., Doetsch, P. W. and Deutsch, W. A. 1996. A Drosophila ribosomal protein contains 8-oxoguanine and abasic site DNA repair activities. EMBO J. 15: 2306-2312. 